\title{
Health claims in the labelling and marketing of food products:
} the Swedish food sector's Code of Practice in a European perspective

\author{
Nils-Georg Asp and Susanne Bryngelsson
}

SNF Swedish Nutrition Foundation, Ideon Science Park, Lund, Sweden

\begin{abstract}
Since 1990 certain health claims in the labelling and marketing of food products have been allowed in Sweden within the food sector's Code of Practice. The rules were developed in close dialogue with the authorities. The legal basis was a decision by the authorities not to apply the medicinal products' legislation to "foods normally found on the dinner table" provided the rules defined in the Code were followed. The Code of Practice lists nine well-established diet-health relationships eligible for generic disease risk reduction claims in two steps and general rules regarding nutrient function claims. Since 2001, there has also been the possibility for using "product-specific physiological claims (PFP)", subject to premarketing evaluation of the scientific dossier supporting the claim. The scientific documentation has been approved for 10 products with PFP, and another 15 products have been found to fulfil the Code's criteria for "low glycaemic index". In the third edition of the Code, active since 2004, conditions in terms of nutritional composition were set, i.e. "nutrient profiles", with a general reference to the Swedish National Food Administration's regulation on the use of a particular symbol, i.e. the keyhole symbol. Applying the Swedish Code of practice has provided experience useful in the implementation of the European Regulation on nutrition and health claims made on foods, effective from 2007.
\end{abstract}

Keywords: disease risk reduction; functional foods; nutrient functions; nutrients; other substances; scientific substantiation

\section{Introduction and background}

$\mathrm{T}$ he first edition of the Swedish Food Sector's Code of Practice on health claims in the labelling and marketing of food products (hereafter referred to as "the Code") was published and implemented in August 1990. The background was the increasing scientific documentation of diethealth relationships as a basis for national and international nutrition recommendations and dietary guidelines based on this science. The food industry showed an increasing interest in providing products with nutritionally adapted composition and wanted to claim health benefits in their marketing of such products.

In Sweden, there was an increasingly intense debate as to whether it was reasonable to have on the one hand official dietary recommendations aiming at preventing diet-related diseases, and on the other hand a complete prohibition of any health claims with reference to the medicinal products legislation, even regarding well-established and gen- erally recognized diet-health relationships (1). In 1988, a large producer of margarines made farreaching advertisements for a product high in polyunsaturated fat, which was said to be good for people with high cholesterol values. The medical products division of the National Board of Health and Welfare (now the Swedish Medical Products Agency) argued that this was illegal sale of drugs. The marketing was withdrawn. As a result of this case and the above-mentioned discussions, a working group representing the authorities decided, in 1989, that "medicinal products legislation should no longer apply to foods normally found on the dinner table" (2). One condition for this was that no dosage instructions or other information used only for medicinal products be used in the marketing. The exception did not include preparations sold in pharmaceutical-like forms, such as tablets or capsules, even if these were made from food raw materials. 
Another important basis for the Code was an increasing focus on the primary responsibility of companies to prevent and solve consumer and marketing problems. For these reasons voluntary measures in the form of self-regulating programmes appeared. Accordingly, the authorities encouraged the food sector to establish such a self-regulating programme regarding the use of health claims in the labelling and marketing of food products (2).

\section{Development of the first edition of the Code}

The first edition of the Code, from 1990 (2), was developed in consultation with the competent authorities and their expert group on diet, health and physical activity, and closely related to the official nutrition recommendations. The principals of the Code were the main organizations of food manufacturers and retailers, at present the Swedish Food Federation (Li) and the Swedish Food Retailers Federation, respectively. The SNF Swedish Nutrition Foundation had an advisory and coordinating role. A health claim was defined as a statement on a health-related advantage of a food product, e.g. in relation to description of the composition of the food. The Code focused around generally accepted diet-health relationships (Table 1).

As important general rules, it was stated that marketing and information using health claims should contribute to consumers' insight into the diet-health relationship, and that claims should be concordant with general nutrition recommendations and have generally recognized scientific support. Health claims should be made in relation to a

Table I. Diet-health relationships approved for generic health claims according to the Swedish Code of Practice: wording according to the two-step principle was required from the second edition (3)

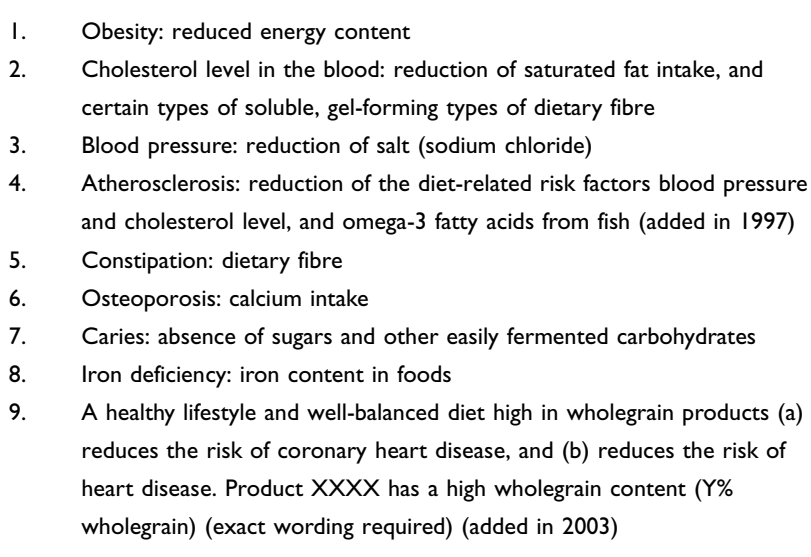

balanced diet and used only for products that with normal use have an impact on the total dietary composition.

In the first edition (2) there was a specific comment about general, vague claims such as "good for the skeleton, the heart, the stomach" and "normalizes the intestinal flora". Such claims should be used sparingly and only in combination with an explanatory text, and must be established and documented.

Regarding product-specific claims implying that a certain product has an effect on, for instance, blood cholesterol or blood pressure, it was stated that such claims require well-documented and published studies of the product or an identical product. Since delimitation towards medicinal products was regarded as difficult in such cases, premarketing consultation with the Medical Products Agency was recommended.

Claims about blood glucose reducing effects were not allowed in the first edition, with reference to the fact that foods for people with diabetes were not approved as foodstuffs for particular nutritional uses in Sweden. Further, no claims were allowed regarding any diet-cancer relationships, which was in any case not explicitly wished for by the industry.

An internal evaluation in 1993 (4) concluded that health claims had been made mainly for spreads, edible oils and fermented milk products, and also for cereals, mineral salts and mineral water, and that at least 30 new products with health claims had been launched. Regarding product-specific claims, the experience, particularly from marketing of probiotic products, indicated the need for premarket evaluation of the scientific documentation.

\section{Second edition, effective from 1997}

A revision of the Code was made in 1994-96 and the second edition of the Code was applicable from 1997 (3). At that time, the Swedish food legislation had been harmonized with that of the European Union (EU) (from 1994 within the European Economic Agreement; Sweden became an EU member from 1995). The most important points in the revision were that:

- A health claim, defined as an assessment of the positive health effects of a foodstuff, must consist of two steps: information on the diet-health relationship, followed by information on the composition of the product. Only this type of 
two-step health claim was dealt with in the revised Code, and examples of approved and non-approved claims were given in an appendix.

- More clear distinctions were made between health claims, nutrition claims and nutrient function claims.

- A claim regarding naturally occurring omega-3 fatty acids in fish/fish products and risk of atherosclerosis and associated cardiovascular diseases was introduced.

- A special comment was made that claims regarding the effect of a foodstuff on the blood sugar level after a meal may fall within the framework of nutrient function claims, provided that the claims are not related to disease or the risk of disease. An example of a claim regarding a generally accepted property of this kind was given: "The carbohydrates in pasta lead to a low, slow increase in blood sugar level" (the glycaemic index was more specifically addressed in the 2004 edition of the Code; see below).

- The previous possibilities for product-specific claims within the Code were removed.

In spite of increasing evidence of associations between intake of fruit and vegetables and lower risk of several cancers, claims regarding diet and cancer were excluded also from the revised programme, which was explicitly required by the competent authorities. One reason was difficulties in applying the two-step principle, since possible protective effects could not be connected with specific food components.

With these revisions, the competent authorities continued to support the Code, and a reference to it was kept as "general advice" in the Ordinance on Labelling and Presentation of Foodstuffs (5).

\section{Towards product-specific physiological claims}

The increasing interest in developing foods with health benefits above "normal nutrition" warranted a special comment in the revised Code (3): "It is the intention of the food industry to take up the matter of 'functional foods' in a supplement to this programme." One main reason for this was the great interest in Sweden in developing microorganisms with specific health-promoting effects and market probiotic products containing such microorganisms with health claims. Numerous and often far-reaching health claims appeared on the market. The authorities made interventions prohibiting certain claims, but there were problems in classifying these products. Some were temporarily registered as "natural remedies". Claims regarding effects of oligosaccharides on the intestinal flora (bifidogenic effects) also started to appear on the market. In 1996, the National Food Administration (NFA) listed a number of prohibited claims for probiotics (6), some of which, however, have continued to be used in the marketing of such products.

A working group was set up within the SNF and, in 1998, formulated a proposal for an extension of the Code to cover also "Product-specific physiological claims", abbreviated to PFP in Swedish (7-9). At that time the Functional Foods Science in Europe project, FUFOSE, was about to be completed (10). In this project, "enhanced function claims" and "disease risk reduction claims" were specified, and the distinction was made between claims about disease risk reduction through a suitable diet including "functional foods" and prevention that can be claimed only for medicinal products. FUFOSE suggested that disease risk reduction claims should be allowed for food products if an effect on an established marker (risk factor) had been demonstrated. The development of the Dutch "Code of Practice assessing the scientific evidence for health benefits stated in health claims on food and drink products" (11) provided another important input in this work.

The PFP corresponded mainly to "enhanced function claims", and was defined as meaning "a claim concerning the health-promoting effect of the product in itself"'. As for other parts of the Code, the products should be part of a normal diet and not dietary supplements or other substances in the form of capsules, tablets, dragées, powders or the like. Human intervention studies were required, performed on study groups representative of the intended consumers, with realistic amounts of the product related to normal use and long enough to show a lasting effect. Premarketing evaluation by internationally well-reputed scientists was required. Furthermore, a new lawyer-led body for follow-up was suggested, "The Assessment Board for DietHealth Information" (abbreviated to BKH in Swedish).

Later in the same year, 1998, the NFA published, on the request of the Government, its first report with an analysis of health claims $(12,13)$. The legal situation in different countries was described and 
different alternatives for handling health claims were discussed. The previous standpoint was maintained that generic claims in two steps, based on well-documented diet-health relationships, could be accepted without considering the product as a medicine even if a specific disease was mentioned. The need for additional considerations was expressed, especially in relation to developments that had started within the EU, for instance regarding the possibility of using product-specific claims without interference with the medicinal products legislation.

In 1999 there were interpellations and questions in the Swedish Parliament regarding product-specific health claims. The Minister of Agriculture responded and the Department of Agriculture arranged hearings with stakeholders. The Government assigned the NFA to clarify (after consultation with the Medical Products Agency and the Swedish Consumer Agency) reasons for enabling productspecific health claims, and to provide a basis for further input in the continued work within the EU. This report was published in April 2000 (14, 15). The main alternative was regulation of productspecific health claims, implying application to the competent authority and approval of both the product and the health claim. A possibility mentioned awaiting EU regulation was to extend the Code to include product-specific physiological claims according to the PFP report (7), which was attached as an appendix to the report. In a third report in June 2001 (16) the NFA included a further analysis of "functional foods" and focused on suggestions on a legal framework that could be compatible with the forthcoming EU Regulation, as well as on documentation of effects and safety aspects.

In response to a further interpellation in Parliament on 27 March 2001, the Minister of Agriculture invited the SNF to develop the Code according to the PFP report (7) in collaboration with the food sector and the consumer organizations that had previously expressed their support for an extended Code (17). This was also regarded as a possible temporary solution in the analysis by the NFA (16). The extension of the Code to product-specific physiological claims was launched from September 2001 (18).

The extension of the Code included a specific body for follow-up: the Assessment Board for DietHealth Information (BKH). The task of this new, lawyer-led body, as regulated in its statutes (19), includes issuing statements, either on its own initiative or on request from a private person, manufacturer, a coalition of manufacturers, consumers or employees concerning whether a particular marketing action or other action relating to the labelling or marketing of foods complies with good business practice according to the Code $(19,20)$.

\section{The 2004 edition of the Code}

The second revision of the Code was carried out in 2003-2004 and a third edition (20) became effective in September 2004. As in the previous editions, general reference was made to labelling regulations, directives and practices requiring that marketing information be reliable, objective and not misleading. The following main new items and completions were made:

- It was specifically stated that health claims dealt with in the Code included "all claims related to health, performance and well-being".

- The different types of health claims dealt with in the Code - two types of generic claims, i.e. nutrient function claims and generic reduction of disease risk claims, and product-specific physiological claims - were more clearly defined and illustrated by examples.

- The additional generic disease risk reduction claim regarding wholegrain and risk of (coronary) heart disease, No. 9, introduced in 2003, was included.

- Conditions for use of the various types of claims in terms of nutritional composition of eligible products, i.e. nutrient profiles, were introduced.

Appendices 1-3 of the Code (20) are reproduced as appendices to this article. Appendix 4 contains the statutes of BKH (19) and Appendix 5 comments on nutrition claims with reference to relevant regulations, nutrition declaration/labelling with listing of vitamins and minerals that may be declared, the keyhole symbol, recommendations regarding product groups, and claims regarding blood sugar and cholesterol.

Table 2 shows the different claims specified in the Code, compared with health claims according to the Codex Alimentarius Guidelines (21) and the EC Regulation effective from 1 July 2007 (22, 23). Product-specific physiological claims would correspond primarily to other function claims in the 
Table 2. Claims specified in the Swedish Code, compared with Codex Alimentarius guidelines (2I) and EC Regulation (22)

\begin{tabular}{|c|c|c|}
\hline Swedish Code 2004 & Codex Alimentarius guidelines 2004 & EC Regulation 2007 \\
\hline $\begin{array}{l}\text { Nutrient function claims (generic); } \\
\text { product-specific physiological claims }\end{array}$ & $\begin{array}{l}\text { Nutrient function claims; } \\
\text { other function claims }\end{array}$ & $\begin{array}{l}\text { Article } 13 . \text { Health claims other than those referring to the } \\
\text { reduction of disease risk and to children's development and health }\end{array}$ \\
\hline Reduction of disease risk claims (generic) & Disease risk reduction claims & $\begin{array}{l}\text { Article 14. Reduction of disease risk claims and claims referring to } \\
\text { children's development and health }\end{array}$ \\
\hline
\end{tabular}

Codex guidelines, whereas these claims will probably apply to Article 13 in the EC Regulation, together with the nutrient function claims.

\section{Generic claims}

Regarding nutrient function claims, it was stated in the Code (20) that such claims "may only be made for generally accepted nutritional physiological functions ..." and that "... functions shall also be relevant for Swedish consumers." It was recommended, but not absolutely required to express nutrient function claims in two steps, i.e. a nutrition claim combined with information about a certain generally accepted physiological role of the nutrient in question. Some examples of acceptable nutrient function claims that were considered relevant to Swedish conditions were given in an appendix, as well as some examples of scientifically true, but for Swedish conditions irrelevant claims (Appendix 1). However, the Code did not provide any positive list of nutrient function claims, which will be established according to Article 13 in the new EC Regulation $(22,23)$. Nutrition labelling that includes the nutrient in question was required explicitly, which means that the amount of the nutrient must meet the labelling conditions, e.g. $15 \%$ of recommended daily intake (RDI) per $100 \mathrm{~g}$ or $100 \mathrm{ml}$.

The generic reduction of disease risk claims, listed in Table 1 and Appendix 2, with examples of wordings, are closely related to the official Swedish Nutrition Recommendations (1996 or later updates, now based on 24), and thus relate to generally recognized and scientifically well-documented connections between diet and a reduced risk of dietrelated diseases.

Regarding wording, as in the previous edition, the requirement is stated that "Generic reduction of disease risk claims must be given in two separate parts, that is, information on the product's composition and the generally accepted connection between diet and a reduced risk of disease."
The requirement to put the claim into a dietary context was worded as follows: "A claim must provide enough information to enable the consumer him-/herself to evaluate the claim and must give a balanced overall picture of the cause and effects described in the marketing. The wording of generic reduction of disease risk claims must therefore take into account the requirements for the composition of a balanced diet that provides all of the different nutrients." This is in agreement with Article $3 \mathrm{~d}$ in the EC Regulation (22).

\section{Nutrient profiles}

Nutrient profiles were specified in the third edition of the Code, as given in Appendix 2. In previous editions general conditions regarding the nutritional composition of products with health claims had been expressed, e.g. to "promote a generally nutritious diet" or "not clash with dietary guidelines". For disease risk reduction claims the keyhole criteria were generally required when applicable. Since the keyhole criteria were under revision at that time, complementary conditions for sugars and fat, for example, were specified by the Code. However, when the revision of the keyhole rules was completed on 1 June 2005, the new conditions, including maximum levels for the content of fat, sugars and salt and minimum levels of dietary fibre, were adopted (25). The keyhole criteria are category based, and vary for the 26 different food groups included. However, the Code allows claims for a few product categories not covered by the keyhole rules, e.g. vegetable oils, and additional conditions for these products were therefore established.

\section{Product-specific claims}

Regarding product-specific physiological claims, a premarketing evaluation procedure for the scientific substantiation of claims had been organized by $\mathrm{SNF}$, and the requirements were defined as follows: 
A product-specific physiological claim (abbreviated PFP in Swedish) must be substantiated by studies that demonstrate the claimed effect using scientifically sound methods. The company marketing the product must be able to provide documentation of these studies. The studies must be conducted on humans and the trial group used should be representative of the product's target group. The studies must represent intake levels that correspond to normal use of the food for the trial period, and be of sufficient duration to demonstrate the intended effect.

The handling process for documentation submitted to SNF for scientific evaluation is described in Appendix 3. SNF's research committee had the task of selecting appropriate experts to carry out the evaluation on a case-by-case basis (18).

It was further stated:

The food product must provide a specific, documented physiological effect and be intended for consumption as a part of a nutritionally balanced diet. Characteristically, the product is marketed with claims related to this effect. The product must have a declaration of nutritional value according to group $2 \ldots$ and must state the amount to be consumed to achieve the claimed physiological effect.

Ingredients of the foods evaluated for PFP claims must be classified as food raw materials or approved additives, and where applicable must have undergone safety testing in accordance with the EC Regulation on novel foods. $\mathrm{SNF}$ makes sure that this is the case before beginning an evaluation. The Research Committee or experts retained by the committee do not, as a rule, make decisions concerning safety issues.
Since the introduction of product-specific physiological claims in 2001, 34 applications for evaluation of scientific dossiers have been handled, together with 18 applications for evaluation of the "low glycaemic index" claim according to the simplified procedure described below (August 2007). The 11 products with approved documentation have claims related to blood glucose excursions, mild gastrointestinal complaints and blood cholesterol/ low-density lipoprotein cholesterol levels (Table 3). In addition, 15 products (including ready-to-eat meals, breads, mueslis and a snack meal) have been approved for the use of a "low glycaemic index" claim (26).

In the Netherlands product-specific claims have been permitted according to the Dutch "Code of Practice assessing the scientific evidence for health benefits stated in health claims on food and drink products", introduced in 1998 on the initiative of the Netherlands Nutrition Centre (11). This Code regards voluntary evaluation of the scientific evidence behind planned product-specific health claims on foods and drinks. At the time of writing (September 2007), eight products have passed this evaluation with a positive result, as listed in Table 4.

\section{Comments on specific issues related to the Swedish Code}

The two scientific expert panels related to the Code have been the NFA's expert group on diet and health, and SNF's research committee. Some issues handled by these expert groups at the latest revision and more recently are commented on below. For the generic claims, discussions have been closely related to the official nutrition recommendations, and a reference to the scientific basis for these has

Table 3. Products with documentation approved for product-specific physiological claims (September 2007) (26)

\begin{tabular}{|c|c|c|c|}
\hline Product & Manufacturer (year) & Description & Physiological claim \\
\hline Primaliv & Skånemejerier, Sweden (2002) & Yoghurt and muesli with beta-glucans & Blood glucose levels \\
\hline Becel pro.activ (with plant sterols) & Unilever Sverige (2002) & Yoghurt drink (shot), milk drink and spread & Blood cholesterol level \\
\hline ProViva (with Lactobacillus plantarum 299v) & Skånemejerier, Sweden (2003) & Fruit drink and shot & Intestinal gas formation \\
\hline Julia/Hjärtans Lust & Skånemejerier, Sweden (2004) & Margarine cheese based on rapeseed oil & Blood cholesterol level \\
\hline Benecol (with plant sterols) & Raisio, Finland (2006) & Spread and yoghurt drink & Blood cholesterol level \\
\hline $\begin{array}{l}\text { LGG }{ }^{\circledR} \text { Plus (with L. rhamnosus GG, L. rhamnosus } \\
\text { Lc705, P. freudenreichii ssp. shermanii JS and } \\
\text { B. animalis/lactis) }\end{array}$ & Valio, Finland (January 2007) & Milk drink & Bowel comfort \\
\hline Primaliv muesli & $\begin{array}{l}\text { Skånemejerier, Sweden (2006, } \\
\text { posted sept 2007) }\end{array}$ & Muesli with beta-glucans & Blood cholestrol level \\
\hline
\end{tabular}


Table 4. Products that have passed the scientific evaluation within the Dutch Code with a positive result (II)

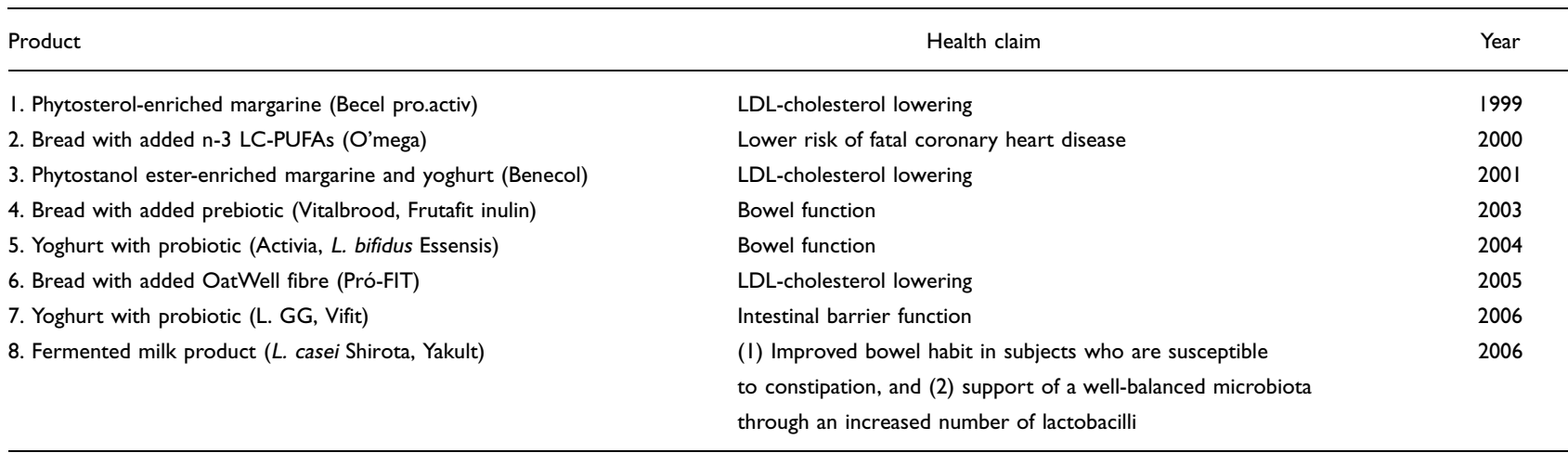

LDL: low-density lipoprotein; LC-PUFA: long-chain polyunsaturated fatty acid.

generally been made (24). Discussions have also related to generic claims approved in the UK, according to the Joint Health Claims Initiative (JHCI), established in 2000 (27) as a joint venture between consumer organizations, enforcement authorities and industry trade associations. This Code of Practice defines both generic and product-specific (innovative) claims. Until closing down on 31 March 2007, however, only generic claims (Table 5) had been approved. In addition to the JHCI claims, claims approved by the US Food and Drug Administration (FDA) have been considered.

\section{Certain types of soluble dietary fibre and blood cholesterol}

Regarding claims on the connection between certain types of soluble fibre and blood cholesterol levels, it

Table 5. Approved generic claims within the UK Joint Health Claims Initiative (JHCl) (27)

\begin{tabular}{ll}
\hline Date & \multicolumn{1}{c}{ Claim } \\
\hline 12 October 2001 & $\begin{array}{l}\text { Generic health claim for reduced saturated fat and blood } \\
\text { cholesterol } \\
\text { Generic health claim for wholegrain foods and heart } \\
\text { health } \\
\text { 04 February 2002 }\end{array}$ \\
$\begin{array}{ll}\text { Generic health claim for soya protein and blood } \\
\text { cholesterol } \\
\text { II February 2005 }\end{array}$ & $\begin{array}{l}\text { Generic health claim for oats and blood cholesterol } \\
\text { Gnder consideration but not available for use under current food law } \\
\text { I5 February 2002 }\end{array}$ \\
$\begin{array}{l}\text { Generic health claim for fruit and vegetables and stomach } \\
\text { cancer } \\
\text { I5 February 2002 }\end{array}$ & $\begin{array}{l}\text { Generic health claim for fruit and lung cancer } \\
\text { Generic health claim for vegetables and bowel cancer }\end{array}$ \\
\hline
\end{tabular}

PUFA: polyunsaturated fatty acid was recommended in the third edition of the Code (20) that such claims be used primarily for oat fibre (beta-glucans, Appendix 2, Connection 2b). This was based on the broad consensus on the cholesterol-reducing effect of oat beta-glucan, expressed in the adoption of the corresponding claim by the FDA in 1997 (28) and later on also by the JHCI (27). The requirements set by the FDA, that products eligible for this claim should provide at least $0.75 \mathrm{~g}$ beta-glucan per normal serving or $3 \mathrm{~g}$ beta-glucan per day at a normal amount consumed, were adopted. The claim was approved for rolled oats and oat bran, as well as mixtures that contain these raw materials. Since some food processing can affect the chemical structure of the beta-glucans and thereby reduce the cholesterol-lowering property, substantiation of a retained cholesterol-lowering effect was required for processed foods.

Recently, SNF's research committee reviewed the documentation on cholesterol-lowering effects of barley beta-glucans (29), and concluded that the claim could also be used under similar conditions for barley beta-glucans. Accordingly, the Code also approved the use of this generic claim for barley flour and flakes (30).

\section{Soya protein}

A claim regarding cholesterol-lowering effect of soya protein, approved by the FDA and later also by the JHCI, was considered, but rejected by the expert group on diet and health as less relevant for Swedish conditions.

\section{Omega-3 fatty acids}

When introduced in the 1997 edition (3), claims on the reduced risk of cardiovascular disease were 
allowed only for fish and fish products high in omega-3 fatty acids. In the third edition the claim was extended to be allowed also for other foods with added fish oil, provided that the content of omega-3 fatty acids in the final product was at least $0.7 \mathrm{~g}$ per $100 \mathrm{~g}$, or per serving for products packaged as single servings (Appendix 2, Connection 4).

When detailed conditions of use were established in 2004, the general principle applied to disease risk reduction claims was that foods eligible for a claim shall be a "significant source" of the nutrient in question, i.e. contain $30 \%$ of the RDI per $100 \mathrm{~g}$, or per portion for products packaged as single servings. However, for omega-3 fatty acids "significant source" was not defined in the Directive on labelling (31). Therefore, it was decided to base the condition of use on the nutritional recommendation of a daily intake of $1 E \%$ total omega-3 fatty acids (24). Calculated on a daily energy intake of $2000 \mathrm{kcal}$, $30 \%$ of RDI is $0.7 \mathrm{~g}$ omega- 3 fatty acids. The Code states that foods containing this amount per $100 \mathrm{~g}$ or portion for products packaged as single portions can use a nutrition claim "high in omega-3 fatty acids", and if the level is half of this (i.e. $15 \%$ of RDI) a nutrition claim "contains omega-3 fatty acids" may be used.

Health claims regarding decreased risk of cardiovascular disease were allowed only for foods high in long-chain omega-3 fatty acids from fish, and not for those high in omega-3 fatty acids from vegetable oils ( $\alpha$-linolenic acid). Although the level of omega3 fatty acids set as a condition for this claim, $0.7 \mathrm{~g}$ per $100 \mathrm{~g}$, was derived from recommendations of total omega-3 fatty acids intake, both SNF's research committee and NFA's expert group on diet and health supported the condition for using the claim to be $0.7 \mathrm{~g}$ omega-3 fatty acids from fish per $100 \mathrm{~g}$, i.e. long-chain omega-3 fatty acids. The rationale behind this was that the claim is based on epidemiological studies showing a connection between intake of fish and a lower incidence of cardiovascular disease, as well as intervention studies using gram doses of long-chain omega-3 fatty acids. For example, one portion of fish provides 1-5 $(-10) \mathrm{g}$ long-chain omega-3 fatty acids.

The JHCI approved a generic claim on omega-3 fatty acids in 2005 (Table 5). For that claim, $0.2 \mathrm{~g}$ omega-3 fatty acids per serving is required for foods presented as a standalone serving. However, the following statement is also required: "The Govern- ment advises that at least two servings of fish, one of which should be oily, containing approximately $3 \mathrm{~g}$ long-chain n-3 polyunsaturated fatty acids, is consumed per week."

In the EC Regulation both nutrition claims and health claims regarding omega-3 fatty acids encounter problems since the Annex to the Regulation does not list any claims corresponding to "high in omega-3 fatty acids" and the labelling directive (31) does not define "source of omega-3 fatty acids". However, in 2005 EFSA suggested the nutrition claims "omega-3 fatty acid source" and "high in omega-3 fatty acids" for foods containing $15 \%$ and $30 \%$ of the recommended nutritional intake $(2 \mathrm{~g}$ per day) per $100 \mathrm{~g}, 100 \mathrm{ml}$ or $100 \mathrm{kcal}$, respectively (32), which is slightly lower than the levels used in the Code. The proposed claims did not distinguish between short-chain and long-chain omega-3 fatty acids. However, it would be helpful if conditions for claims for both of these categories of omega-3 fatty acids were introduced in the Annex to the EU Regulation (22).

\section{Dietary fibre}

For the fifth claim, on dietary fibre and bowel regularity/decreased risk of constipation, products are required to comply with the keyhole criteria when applicable and to have "high" content of dietary fibre (Appendix 2, Connection 5). At the time of the latest revision, "high fibre" was defined as at least $3.5 \mathrm{~g}$ dietary fibre per $1000 \mathrm{~kJ}$. In 2005 this was changed to comply with the new keyhole criteria, i.e. $4.5 \mathrm{~g}$ per $1000 \mathrm{~kJ}$ (25). Furthermore, normal consumption of the product should provide at least $5 \mathrm{~g}$ dietary fibre, which is $20 \%$ of the minimum recommended intake of dietary fibre. If more than $20 \%$ of the fibre was derived from fibre concentrates or isolates, substantiation of laxative effects was required.

\section{Wholegrain}

In 1999, the FDA allowed use of the following health claim: "Diets rich in wholegrain foods and other plant foods and low in total fat, and saturated fat, and cholesterol may reduce the risk of heart disease and some cancers". In 2002, the JHCI published an authoritative endorsement that wholegrain foods are associated with a healthy heart, and allowed the following claim: "People with a healthy heart tend to eat more wholegrain foods as part of a healthy lifestyle" $(27,33,34)$. 
The wholegrain health claim was introduced in the Code in 2003 as supported by NFA's expert group on diet and health and by SNF's research committee, which stated:

\begin{abstract}
After having considered the epidemiological studies and reviews available, the research committee expressed the following opinion: There is a consistent epidemiological association between consumption of wholegrain cereal products and lower risk of ischaemic (coronary) heart disease (IHD). The relationship is seen in different populations and at different levels of intake. The relationship is stronger for wholegrain than for cereal fibre. It is not known which component(s), or combination of components, that convey the protective effect. Intervention studies are lacking. The surveys published as review articles, and the recent evaluation within the UK JHCI can be regarded as sufficient to support the epidemiological relationship between consumption of wholegrain cereal products and a "healthy heart", i.e. diminished risk of IHD (33).
\end{abstract}

The reason for requiring an exact wording for this claim according to one of two alternatives, i.e. mentioning lifestyle and well-balanced diet, was the fact that this claim is based mainly on observational, i.e. epidemiological studies in which the wholegrain consumption covariates with other positive lifestyle factors. A similar view is reflected in the claim as approved by the JHCI (27).

The conditions for the use of the wholegrain claim according to the Code (Appendix 2) are that flours, grains and flakes must be $100 \%$ wholegrain, and other products including breakfast cereals and bread must have at least $50 \%$ wholegrain based on the dry matter. Wholegrain is defined as containing all components of the grain and limited to wheat, oats, barley and rye. Furthermore, the dietary fibre content must be at least $4.5 \mathrm{~g}$ per $1000 \mathrm{~kJ}$ and conditions regarding fat, sugar and salt content of for the keyhole must be fulfilled.

\section{Fruit and/or vegetables}

The possibility of introducing a disease risk reduction claim for fruit and vegetables was further considered in the 2004 revision, as expressed in a comment in Appendix 2 (last paragraph). Although epidemiological studies suggest a connection between a high intake of fruit and vegetables and reduced incidence of cardiovascular disease and certain types of cancer, it was decided not to include any specific health claims on fruit and/or vegetables. Instead, reference was made to the possibility of citing more generally the official recommendation to eat $0.5 \mathrm{~kg}$ fruit and vegetables daily (potatoes not included).

Although it is still not known which nutrients or other substances are the most important factors behind these associations, specific health claims for fruit and vegetables should be considered further in analogy with the wholegrain/reduced risk of heart disease claim.

The JHCI approved claims for fruit and vegetables and stomach cancer, fruit and lung cancer, and vegetables and bowel cancer (Table 5). However, since food law was interpreted as prohibiting mentioning any disease, these claims were considered as not available for use.

\section{Glycaemic index}

The glycaemic index (GI; incremental area under the blood glucose elevation after standardized ingestion of the food product as a percentage of the corresponding area after glucose) has been the subject of considerable research recently, and also controversy regarding its applicability and importance. It is also used, and misused, extensively in the public debate, as well as in marketing. GI is frequently mixed up with glycaemic load (GL, defined as GI $\times$ amount of carbohydrate in a serving, meal or diet).

The handling of GI in the Code was based on discussions with Scandinavian scientists in the area, which resulted in a state-of-the-art article (35). Claims regarding effects on the postprandial blood glucose level, including claims on low GI, are considered as product-specific physiological claims (PFP), with the exception of pasta products, for which a nutrient function claim is allowed, e.g. "The carbohydrates in pasta provide a low and gradual increase in blood sugar (or have a low GI)" $(3,20)$.

Being a kind of quality measure for carbohydrates, related to their rate of digestion and absorption, specific GI labelling has been regarded as relevant only for foods providing significant amounts of digestible carbohydrates, i.e. $15 \mathrm{~g}$ or preferably $20 \mathrm{~g}$ per normal serving, and only if there is a significant variation between different products within the actual food category. Examples of products for which GI labelling has not been considered as relevant so far are cow's milk products, since these induce a high insulin response. 
Foods not contributing to a nutritionally balanced diet, e.g. biscuits high in fat or sugars, have also been considered as ineligible for GI labelling. Furthermore, GI labelling has not been approved for foods where the carbohydrates are mainly added fructose.

Provided that the criteria specified in Box 1 are fulfilled, evaluation of the documentation of "low GI" has been handled by a simplified procedure (one external expert), compared to other PFP applications (Appendix 3). Awaiting the implementation of the EU Regulation, the Code will continue to provide, through SNF, the opportunity to have a product evaluated regarding its suitability for labelling with low GI, including an evaluation of the GI determinations used to support the application. Evaluated products will continue to be listed on the website of the Code (26).

\section{The Assessment Board for Diet-Health Information}

In connection with the extension of the Code in 2001, a new lawyer-led body was set up, the Assessment Board for Diet-Health Information $(\mathrm{BKH})$, with the following main tasks expressed in the charter $(19,20)$ :

§2 The assignment of the Board (BKH) is to make independent statements, on receipt of queries, as to whether a particular marketing action or other action in connection with the labelling and marketing of food products com- plies with good marketing practice according to "Health Claims in the Labelling and Marketing of Food Products. The Food Sector's Code of Practice", accepted by the responsible organizations, henceforth called "the Code". A statement by the Board (BKH) is not a substitute for actions by the authorities concerned.

\$3 Appeals may be referred to the Board (BKH) against decisions by the Research Committee of SNF Swedish Nutrition Foundation concerning the evaluation of scientific documentation according to the Code.

BKH has published 12 statements, one general guideline type of statement regarding the Code's requirement of premarket evaluation of the scientific evidence behind product-specific health claims, and the other 11 about advertisements and/or panel texts with health claims. Nine of these statements concluded that the marketing measure in question was not in agreement with what can be regarded as "good marketing practice". The statements are made public and available on the website of the Code (26).

BKH has not handled any appeals against the Research Committee's decisions.

\section{Evaluations of the Swedish Code}

An inventory in ordinary shops in March 2000 by Laser Reuterswärd (37) indicated that the most common health claims regarded cholesterol level in the blood (spreads and products with oats/oat fibre) and bowel function/regularity. There was also a

Box I. Criteria for glycaemic index.(GI) labelling according to the Swedish Code (36)

- The Gl value of a specific food product must be determined by studies in humans, using the actual food product. Optimal studies are made with at least 10 healthy subjects, not using drugs that may influence the results. Gl determinations should be made in the morning in fasting subjects.

- Gl determinations should be made according to the methodology described in the FAO/WHO report "Carbohydrates in human nutrition" (1998). The GI value must be based on the product's content of digestible carbohydrates (glycaemic or available carbohydrates), and not on the total carbohydrate content. Negative areas (i.e. areas obtained when the blood glucose level is lower than the fasting level) should not be included when calculating the incremental area under the curve (IAUC). The blood glucose level should be determined on capillary blood samples and the reference (glucose or white bread) should be given to each volunteer at three different occasions.

- Awaiting further standardization of the methodology, Gl determinations from at least two independent laboratories are required.

- The product's $\mathrm{Gl}$ value should be given in relation to a glucose reference. If the determination is made with white bread as reference, this reference has to be calibrated against glucose.

- A product is considered to have a low $\mathrm{Gl}$ if its $\mathrm{Gl}$ value is lower than 55 (glucose $=100$ ) and significantly different from the control in both determinations.

- The product must contain at least $15 \mathrm{~g}$ (preferably $20 \mathrm{~g}$ ) digestible carbohydrates per normal amount consumed at one eating occasion. For most products the content of available carbohydrate can be determined "by difference", i.e. the amount of dietary fibre (determined according to AOAC) is deducted from the total carbohydrate content. However, a specific analysis of the digestible carbohydrates should be made if more than $5 \%$ of the total carbohydrate content may be assumed to consist of non-digestible carbohydrates, that are not determined in the routine dietary fibre analysis. This is the case mainly for food products with added resistant starch, inulin, oligofructose and other non-digestible oligosaccharides.

- Normally, Gl determinations are made on subjects eating an amount of the test product that corresponds to $50 \mathrm{~g}$ available carbohydrates. If this results in an unrealistically large portion of the actual food product, determination may be made with $25 \mathrm{~g}$ available carbohydrates from the test product and reference, respectively. 
clear tendency towards an increased use of nutrient function claims, especially for "PLUS-products", i.e. products enriched with omega-3 fatty acids or vitamins, for example. About 25 probiotic products were on the market with more or less strong product-specific health claims, although such claims were not allowed at that time, either within the legislation or within the Code.

A more extensive analysis of wordings and concepts used in health claims was reported in 2001 by Laser Reuterswärd and Ungerth (38). Many wordings and soft concepts such as "energy" and "balance", not regulated in the Code or elsewhere, were identified. Messages about probiotic effects, blood glucose effects, e.g. on satiety, fibre and satiety, and functional claims for PLUS-products regarding, for instance, oligosaccharides, omega-3 fatty acids and calcium, were the most common types of claim.

\section{External evaluation}

In 2005 an external evaluation of the Code was carried out with a focus on the handling of productspecific physiological claims (39). One reason for the evaluation was the fact that few products had passed the scientific evaluation with a positive statement at that time. The following main conclusions were drawn: (i) the requirements for scientific documentation of product-specific claims had been reasonable; (ii) the Assessment Board (BKH) had been useful but should be completed with a more active follow-up of health claims used on the market, and more rapid decisions and actions against misuses in relation to the Code, than had been possible by BKH; and (iii) the Code was in line with the forthcoming EC Regulation, the first draft having been available since 2003 .

\section{Master's theses}

Two master's (MSc) theses have been written around the Code. One of them (40) reported that 100 health claims were found on 80 products at an inventory in 2004 of three supermarkets belonging to the main retail chains. Of these, 40 were classified as reduction of disease risk claims, 34 as nutrient function claims and 26 as product-specific physiological claims (PFP). The product group with most claims (31 claims) was breakfast cereals and grains; 17 nutrient function claims were found for dietary fibre and bowel function and nine regarded the connection between wholegrains and risk of heart disease. Ten claims were identified that used wording such as "prevent", "avoid" or "counteract", instead of diminished risk for disease. An overall conclusion was that the possibility of using generic claims according to the Code was clearly underutilized.

Another MSc thesis had the title "Wholegrain and health claims - the industry's, consumers' and scientists' opinion" (41). Data on producers' and consumers' opinions on wholegrain were collected through qualitative interviews. This survey was performed in 2005. For surprisingly few consumers wholegrain was a major reason for choosing a certain bread, and there was a clear lack of knowledge of and confidence in health claims. Sugar, fat and fibre content were more commonly considered, as well as colour and "coarseness". Producers regarded consumer education a key issue for increased wholegrain consumption, and expressed reluctance to mentioning disease risk in their marketing.

\section{Concluding remarks}

The Swedish Code of Practice on health claims, in action since 1990, has provided experience useful in the implementation of the EC Regulation on nutrition and health claims on foods. Based on these experiences, priorities that may be useful when establishing positive lists of generic health claims, or for the responsible use of such claims, are suggested in an adjacent paper (42). Generic claims, including disease risk reduction claims in two steps, closely related to the official nutrition recommendations, can be used on a range of food products and thereby help in consumer education and promotion of healthy diets. Product-specific claims based on human studies with the food product in question are few so far, owing to the scientific demands and costs of such studies. The harmonization within the EC obtained through the new Regulation can be expected to provide increased incentives for developing food products eligible for various types of health claim.

\section{References}

All internet references were accessed on 17 August 2007.

1. Sjölin K. Diskussionsunderlag [Discussion paper]. Uppsala: Statens Livsmedelsverk [National Food Administration]; 1989. Dnr 3686/89. (In Swedish.) 
2. Hälsoargument i marknadsföringen av livsmedel [Health arguments in the marketing of foods]. Lund: Swedish Nutrition Foundation; 1990.

3. Health claims in the labelling and marketing of food products. The food industry's rules (self-regulating programme). Lund: Swedish Nutrition Foundation; 1997.

4. Asp N-G, Laser Reuterswärd A. Utvärdering av livsmedelsbranschens regler (egenåtgärdsprogram) Hälsoargument i marknadsföringen av livsmedel augusti 1990-juli 1993 [Evaluation of the food sector's rules "Health arguments in the marketing of foods", August 1990-July 1993]. Lund: Swedish Nutrition Foundation; 1994. (In Swedish.)

5. Regulations on the Labelling and Presentation of Foodstuffs. Uppsala: Statens Livsmedelsverk [National Food Administration]; SLVFS 1993:19.

6. Alsén-Eklöf E. Strid om nyttiga mejeriprodukter. Livsmedelsverket avkräver branschen dämpad marknadsföring [Fight on wholesome dairy products. The National Food Administration demands the industry to subdue the marketing]. Livsmedelsteknik 1997; 3: 11. (In Swedish.)

7. Produktspecifika fysiologiska påstående (PFP) - förslag till utvidgning av egenåtgärdsprogrammet [Productspecific physiological claim - proposal for expanding the Code of Practice]; 1998. http://www.snf.ideon.se/snf/ rh/pdf/snf0004.pdf (In Swedish.)

8. Laser Reuterswärd A. Ny rapport med förslag om regler för produkter med dokumenterad effekt [New report with proposals on rules for products with documented effect]. Scand J Nutr 1998; 42: 117-19 (partly in Swedish)

9. Asp N-G, Laser Reuterswärd A. Health claims: the Swedish approach. In: Forum of Functional Food, Proceedings, European Parliament, Strasbourg 1998. p. 241-62.

10. Diplock AT, Aggett PJ, Ashwell M, Bornet F, Fern EB, Roberfroid MB. Scientific concepts of functional foods in Europe - consensus document. Br J Nutr 1999; 81(Suppl 1): 1-27.

11. Code of practice assessing the scientific evidence for health benefits stated in health claims on food and drink products. Netherlands Nutrition Centre (Voedingscentrum) 1998 (1-11). http://www.voedingscentrum.nl/NR/ rdonlyres/84FB9822-8933-4D1B-A8BD-3000A32C1074/ 0/Code_of_Practice_Health_Claimspdf.pdf

12. Lindmark M, Lund B, Sjölin K, Henrysdotter G, Bruce Å, Lindvall C. Utredning och analys av hälsopåståenden vid märkning av livsmedel [Investigation and analysis of health claims in labelling of foods]. December 1998. p. 1-28. www.slv.se/upload/dokument/rapporter/functional_ food/rapport1998_functional.pdf (In Swedish.)

13. Laser Reuterswärd A. SLV och riksdag diskuterar hälsopåståenden [NFA and the government are discussing health claims]. Scand J Nutr 1999; 43: 44. (In Swedish.)

14. Bruce $\AA$. Investigation on health claims about foods. Summary and proposals. Uppsala: National Food Administration; April 2000. p. 1-11. http://www.slv.se/ upload/dokument/rapporter/functional_food/summarys lvrapp6_2000_functional.pdf

15. Norbeli B, Bruce Å. Livsmedel för hälsa och långt liv? Utredning om produktspecifika hälsopåståenden [Foods for health and long life? Investigation on productspecific health claims]. Uppsala: National Food Administration; 2000. Report No. 6/2000. p. 1-102. http:// www.slv.se/upload/dokument/rapporter/functional_food/ slvrapp6_2000_functional.pdf (In Swedish.)

16. Bruce $\AA$, Becker W, Hammerling U, Nilsson J, Sjölin K. Rapport arbetsgruppen för produktspecifika hälsopåståenden [Report of the working group on productspecific health claims]. Uppsala: National Food Administration; June 2001. p. 1-89. http://www.slv.se/upload/ dokument/rapporter/functional_food/rapport2001_func tional.pdf (In Swedish.)

17. Asp N-G. Functional foods, Departementsuppdrag till SNF: Utvidga egenåtgärdprogrammet [Expanding the Swedish Code]. Scand J Nutr 2001; 45: 34. (In Swedish.)

18. Asp N-G, Trossing M. The Swedish Code on healthrelated claims in action - extended to product-specific physiological claims. Scand J Nutr 2001; 45: 189.

19. Charter of the Assessment Board for Diet-Health Information (BKH) in the labelling and marketing of food products. Scand J Nutr 2001; 45: 192.

20. Health claims - in the labelling and marketing of food products. The food sector's Code of Practice. Lund: Swedish Nutrition Foundation; 2004. http://www. hp-info.nu/SweCode_2004_1.pdf

21. Codex Alimentarius. Guidelines on health claims; 2004. http://www.codexalimentarius.net/download/standards/ 351/CXG_023e.pdf

22. Regulation (EC) No. 1924/2006 of the European Parliament and of the Council of 20 December 2006 on nutrition and health claims made on foods. Official Journal of the European Union; 18 January 2007. http:// eur-lex.europa.eu/LexUriServ/LexUriServ.do?uri =OJ:L: 2007:012:0003:0018:EN:PDF

23. Laser Reuterswärd A. The new EC Regulation on nutrition and health claims - from a Swedish perspective. Scand J Food Nutr 2007; 51: 100-6.

24. NNR - Nordic Nutrition Recommendations 2004. 4th edn. Copenhagen: Nordic Council of Ministers; 2004.

25. National Food Administration's Regulations on the Use of a Particular Symbol. LIVS FS 2005:9. http:// www.slv.se/upload/nfa/documents/food_regulations/Key hole_2005_9.pdf

26. Website of the Swedish Code. http://hp-info.nu/ (In Swedish.)

27. Joint Health Claims Initiative - Code of Practice on health claims on foods. London; 2000. http:// www.jhci.org.uk/info/code.pdf

28. Food labeling: health claims; soluble fiber from whole oats and risk of coronary heart disease. FDA; 1997. http://www.cfsan.fda.gov/ 1rd/fr970331.html

29. Åman P. Cholesterol-lowering effects of barley dietary fibre in humans: scientific support for a generic health claim. Scand J Food Nutr 2006; 50: 173.

30. Samband 2b: Minskad risk för hjärt-kärlsjukdom kolesterolnivå i blodet - vissa lösliga kostfibrer 
[Connection 2b: Reduced risk of cardiovascular disease/ atherosclerosis - blood cholesterol levels - certain types of dietary fibre]. http://www.snf.ideon.se/snf/hp_ff/allmanna_2b_havre_korn.htm (In Swedish.)

31. Council Directive 90/496/EEC of 24 September 1990 on nutrition labelling for foodstuffs.

32. EFSA opinion omega-3. Opinion of the NDA Panel Related to Nutrition Claims concerning omega-3 fatty acids, monounsaturated fat, polyunsaturated fat and unsaturated fat. EFSA J 2005; 253: 1-29. Panel on Dietetic Products, Nutrition and Allergies, European Food Safety Authority.

33. Marquart L, Asp N-G, Richardson P. Whole grain health claims in the United States, United Kingdom and Sweden. In: van der Kamp JW, Asp N-G, Miller Jones J, Schaafsma G, eds. Dietary fibre - bio-active carbohydrates for food and feed. The Netherlands: Wageningen Academic Publishers; 2004. p. 39-57.

34. Schmitz K, Asp N-G, Richardson DP, Marquart L. Global regulation, labeling, claims and seals: perspectives and guidelines. In: Marquart L, Jacobs DR Jr, McIntosh GH, Poutanen K, Reicks M. Whole grains health. Ames, IA: Blackwell; 2007. p. 309-316.

35. Arvidsson-Lenner R, Asp NG, Axelsen M, Bryngelsson S, Haapa E, Jarvi A, et al. Glycaemic index: relevance for health, dietary recommendations and food labelling. Scand J Nutr 2004; 48: 84-94.

36. Glycaemic index (GI) - criteria/recommendations. http://www.snf.ideon.se/snf/en/rh/GI_en.htm

37. Laser Reuterswärd A. Hur används Livsmedelsbranschens egenåtgärdsprogram? [How is the Swedish food sector's Code used in practice?] Scand J Nutrition/ Näringsforskning 2000; 44: 36-7. (In Swedish.)

38. Laser Reuterswärd A, Ungerth L. "Nyttigt" och "hälsosamt". Om olika budskap till konsumenter ["Wholesome" and "healthy". On different messages to consumers]. Scand J Nutr/Näringsforskning 2001; 45: 193-200. (In Swedish.)

39. Produktspecifika Fysiologiska Påståenden (PFP) - en utvärdering av ett egenåtgärdsprogram [Product-specific physiological claims - evaluation of a Swedish selfregulatory programme]; 2005. http://www.livsmedelsa kademin.se/bilagor/PRODUKTSPECIFIKA $\% 20$ FYSIO LOGISKA $\% 20 \mathrm{P} \% \mathrm{C} 3 \% 85 \mathrm{ST} \% \mathrm{C} 3 \% 85$ ENDEN.pdf (In Swedish.)

40. Lundblad N. Hälsopåstående på livsmedelsförpackningar hösten 2004 [Health claims on food packages in Sweden - a survey autumn 2004]. MSc thesis, Lund; 2004. http://www.snf.ideon.se/snf/hp_ff/ Inventeringhp_2004.pdf (In Swedish.)

41. Månsson C. Fullkorn och hälsopåståenden - vad säger industrin, konsumenterna och vetenskapen? [Wholegrain and health claims - the industry's, consumers' and scientists' opinion]. MSc thesis, Lund; 2006. http:// www.snf.ideon.se/snf/Nyheter/Fullkorn_exjobb_CM.pdf (In Swedish.)

42. Bryngelsson $\mathrm{S}, \mathrm{Asp} \mathrm{N}-\mathrm{G}$. Health claims other than those referring to decreased risk of disease and children's development and health (Article 13 claims) - suggested priorities with reference to the Swedish Code on health claims. Scand J Food Nutr 2007; 51: 127-36. 


\section{Appendices reporduced from the Swedish Code, 2004 edition (20)}

\section{Appendix I: Nutrient function claims: criteria and examples}

\author{
Requirements for products making nutrient function \\ claims
}

For nutrient function claims regarding vitamins and minerals, the general requirement is that the product must contain a "significant amount" (i.e. a minimum of $15 \%$ RDI per $100 \mathrm{~g}$ or serving ${ }^{1}$, Appendix 5) of the actual nutrient. In addition, normal daily consumption of the actual product must provide at least $15 \%$ RDI of the nutrient in question. Where applicable, products making nutrient function claims must meet the criteria for using the keyhole symbol (Appendix 5), and otherwise contribute to a balanced nutritional diet consistent with official nutrition recommendations. Nutrient function claims can with advantage be made in two steps, according to the examples given below.

Meat, fish, shellfish and poultry products contain haem-iron with high bioavailability. Nutrient function claims regarding iron may be made for these products if the iron content is at least $10 \%$ RDI per $100 \mathrm{~g}$ or serving, despite $15 \%$ RDI being needed for nutrient declaration. Normal daily consumption of the actual product must provide at least $10 \%$ RDI of iron.

For products making nutrient function claims regarding dietary fibre, the product must meet the labelling requirements for "contains dietary fibre" (i.e. have a dietary fibre content of at least $2.5 \mathrm{~g}$ per $1000 \mathrm{~kJ}$, Appendix 5). In addition, normal daily consumption of the actual product must provide a minimum of $3.75 \mathrm{~g}$ dietary fibre. ${ }^{2}$

\section{Examples of approved nutrient function claims relevant to Swedish conditions}

Vitamin C/vitamin E/beta-carotene ${ }^{3}$ is an antioxidant that protects the body's cells. Product $\mathrm{X}$ contains vitamin $\mathrm{C} /$ vitamin E/beta-carotene.

Vitamin $\mathrm{C}$ enhances iron absorption. Product $\mathrm{Y}$ contains vitamin $\mathrm{C}$.

Vitamin D helps build bones. Product $\mathrm{Z}$ contains vita$\min \mathrm{D}$.

\footnotetext{
$\overline{1}$ Only for products packaged in single-serving packages, excluding milk where a claim may be made also on a larger package, providing that a normal portion contains at least $15 \%$ of RDI.

${ }^{2} 3.75 \mathrm{~g}$ dietary fibre corresponds to $15 \%$ of the lowest recommended daily intake of dietary fibre $(25 \mathrm{~g})$.

${ }^{3}$ According to Nordic Nutrition Recommendations, NNR 2004, 1 retinol equivalent (RE) equals $1 \mu \mathrm{g}$ retinol (vitamin A) and $12 \mu \mathrm{g}$ beta-carotene. RDI for vitamin A is $800 \mu \mathrm{g}$ (Table 3, Appendix 5), corresponding to $9600 \mu \mathrm{g}$ beta-carotene.
}

Calcium helps build bones. Product XX contains calcium.

Zinc is needed for many of the body's enzyme systems. Product YY contains zinc.

Iron is essential for (a) making blood cells, (b) production of haemoglobin. Product ZZ contains iron.

Dietary fibre helps to maintain normal bowel function. Product XXX contains dietary fibre.

The carbohydrates in pasta provide a low and gradual increase in blood sugar.

\section{Example of claims that are true, but irrelevant for Swedish conditions}

Vitamin A is found in visual pigments and is important for night vision. Product $\mathrm{X}$ contains vitamin $\mathrm{A}$.

\section{Appendix 2: Generic reduction of disease risk claims: background, criteria and examples}

The following connections between diseases, and their risk factors, and diet are considered well established today and can therefore constitute the basis for generic claims regarding reduction of disease risk in the marketing of foods. Every connection is followed here by a short explanation/background as well as specific criteria. The basic requirement is that a health claim only be used in the labelling and marketing of a product that, under normal use, contributes to a nutritionally balanced diet. The nutritional composition of a product must be such that it does not clash with official dietary recommendations. The nutritional composition and normal amount of the product consumed must be significant for the composition of the diet as a whole.

Generic reduction of disease risk claims must be made in two steps. Table 2 gives examples of how generic claims about a reduced risk of disease can be worded. With the exception of Connection 9 (Coronary heart disease Wholegrain), however, the exact wording of the claim is flexible. In the case of Connection 9, only the wording given in Table 2 may be used. The responsibility for the appropriateness of the final wording used in labelling and marketing rests upon the company marketing the product. For advice regarding the wording of claims, SNF Swedish Nutrition Foundation may be contacted.

\section{Overweightlobesity - Energy}

A high energy intake can lead to overweight/obesity. A diet with a low or reduced energy content can therefore reduce the risk for overweight/obesity. Reduced fat content and increased dietary fibre content lower a 
product's energy content. Depending on the nature of the product, reduced sugar content can also contribute to a lower energy content.

\section{Criteria}

Only products with significant relevance to the total energy intake are appropriate for claims regarding overweight/obesity. Products carrying this claim must contain at least $30 \%$ less energy per $100 \mathrm{~g}$ than a comparable normal product. ${ }^{4}$ For example, the claim can be made for products in the following product groups:

dairy products (e.g. yoghurt)

meat products (e.g. sausages)

prepared foods (e.g. complete meals).

Where applicable, the product must also meet the criteria for using the keyhole symbol (Appendix 5). For products packaged as single servings, the total energy content for the serving must be given.

It should be noted that a reduction in sugar content of solid foods does not normally lead to a lower energy content. With regard to liquid products, it should be observed that these may provide less satiety than solid foods. A considerable amount of energy can therefore easily be consumed through the intake of certain liquid products.

\section{Cardiovascular diseaselatherosclerosis - blood cholesterol levels}

\section{(a) Hard fat ${ }^{5}$ (primarily saturated fat) (b) Certain types of dietary fibre}

High cholesterol levels in the blood represent a dietrelated risk factor for atherosclerosis/hardening of the arteries and are thereby connected with cardiovascular disease.

Hard fats contribute to elevated blood cholesterol levels. A nutritionally balanced diet with a low intake of hard fats can therefore reduce the risk of cardiovascular disease/atherosclerosis. A reduced hard fat content can be achieved either by a total reduction in fat, or by substituting hard fats with mono- or polyunsaturated fats.

Certain types of dietary fibre help to reduce blood cholesterol levels. A nutritionally balanced diet rich in these types of fibre can thereby reduce the risk of cardiovascular disease/atherosclerosis.

\footnotetext{
"A "normal product" refers here to a comparable (but not energyreduced) product from the same product category. For example, milk, natural yoghurt and cultured milk products with $3 \%$ fat are considered "normal" products.

${ }^{5}$ The sum of saturated and trans fatty acids.
}

\section{Criteria}

(2a) Only product groups with significant relevance for the total fat content of the diet are appropriate for claims regarding the connection between saturated fat and blood cholesterol levels (Connection 2a). This applies primarily to the following groups:

Cooking and baking fats (max. $80 \%$ fat), oils (100\% fat) intended for cooking, and dressings (max. 30\% fat). A maximum of $10 \%$ of the total fat content can be made up of hard fat. The total fat content and energy content of these products must be clearly stated.

Margarine spreads, meat and dairy products. These products must meet the criteria for using the keyhole symbol (Appendix 5). A maximum of $30 \%$ of the total fat content can be made up of hard fat.

For all product groups, a maximum of $2 \%$ of the total fat content may be made up of trans fatty acids (not including naturally occurring trans fatty acids from animal sources).

Example: In a margarine spread with a total fat content of $30 \%$, the hard fat content may not exceed $9 \mathrm{~g}$ per $100 \mathrm{~g}$ and the trans fatty acid content may not exceed $0.6 \mathrm{~g}$ per $100 \mathrm{~g}$ of the spread.

For many people, a reduction in total fat consumption is desirable, and the total fat content should therefore be clearly stated in the labelling of oils and fats making this claim. Labelling should also state that the product should be used sparingly and is meant as a substitute for a corresponding normal product, and should not represent an additional source of fat.

(2b) The current recommendation is that claims regarding a connection between particular types of dietary fibre and blood cholesterol levels (Connection 2b) be used primarily for oat fibre (beta-glucans). Some food processing can, however, affect the chemical properties of beta-glucans (e.g. molecular weight, solubility and viscosity) such that the cholesterol-lowering effect is reduced.

This claim may be used for rolled oats and oat bran, as well as mixtures that contain these raw materials. For processed foods containing these, or other raw materials high in beta-glucans, a retained cholesterol-lowering effect after processing must be substantiated.

A product making a claim regarding the connection between oat fibre (beta-glucans) and blood cholesterol levels must contain $0.75 \mathrm{~g}$ of beta-glucans per normal serving, or provide $3 \mathrm{~g}$ per day at a normal amount consumed. The packaging should clearly state how much oat fibre (beta-glucans) the product contains as well as the amount of oat fibre (beta-glucans) that should be eaten to achieve a cholesterol-lowering effect.

Where applicable, the product must meet the criteria for using the keyhole symbol (Appendix 5). For example, the total sugar content (mono- and disaccharides) in 
breakfast cereals must be at most $13 \%$. This corresponds to approx. $10 \%$ added sugar in cereals containing only cereal grains. According to the Code, the criteria for added sugars must also be met for other dry products. For (soft) breads, the added sugar content may not exceed $7 \%$. For breakfast cereals, the fat content must not exceed $10 \%$.

\section{Cardiovascular diseaselatherosclerosis - Blood pressure-Salt}

High blood pressure is a diet-related risk factor in atherosclerosis/hardening of the arteries and therefore connected to cardiovascular disease. Regular salt (sodium chloride) contributes to an increase in blood pressure. A nutritionally balanced diet with a low sodium content can therefore lower the risk of cardiovascular disease/atherosclerosis. A low salt content can be achieved either by reducing the total salt content or by replacing sodium chloride with a mineral salt substitute containing potassium.

\section{Criteria}

Products making claims regarding the connection between salt and a reduced risk of cardiovascular disease/ high blood pressure must meet keyhole symbol criteria where applicable (Appendix 5) and have a lower sodium content than the limits given below, based on the product's finished eating weight.

\begin{tabular}{llc}
\hline & Sodium & $\begin{array}{c}\text { Regular } \\
\text { table salt }\end{array}$ \\
\hline $\begin{array}{l}\text { Meat, sausages and other meat } \\
\text { products }\end{array}$ & $0.5 \%$ & $1.2 \%$ \\
Fish products & $0.4 \%$ & \\
Cheese & $0.3 \%$ & $1.0 \%$ \\
Bread & $0.3 \%$ & $0.7 \%$ \\
Crisp bread, crackers and rusks & $0.5 \%$ & $0.7 \%$ \\
Breakfast cereals & $0.4 \%$ & $1.2 \%$ \\
Bouillon, soups and sauces & $0.2 \%$ & $1.0 \%$ \\
Prepared foods & $0.2 \%$ & $0.5 \%$ \\
\hline
\end{tabular}

\section{Cardiovascular diseaselatherosclerosis/hardening of the arteries - Omega-3 fatty acids}

Epidemiological studies have shown a connection between a high intake of fatty fish and a lower incidence of cardiovascular disease. The long omega-3 fatty acids, eicosapentaenoic acid (C20:5n-3, EPA) and docosahexaenoic acid (C22:6n-3, DHA), found in fatty fish have also been shown to have several positive effects on risk factors for cardiovascular disease. A nutritionally balanced diet high in omega-3 fatty acids from fish can therefore contribute to a reduced risk of atherosclerosis and thereby associated cardiovascular diseases.

The omega-3 fatty acid found in vegetable oils is primarily the essential, short omega-3 alpha-linolenic acid (C18:3n-3, ALA). Risk reduction of cardiovascular disease is less well documented for short omega-3 fatty acids than for long omega-3 fatty acids. ALA can be converted to EPA and DHA in the body, but this conversion is reliant on many factors.

\section{Criteria}

The current recommendation is that claims regarding a connection between omega- 3 fatty acids and cardiovascular disease be used only for fatty fish, products thereof, and products containing these raw materials. Products making this claim must contain a minimum of $0.7 \mathrm{~g}^{6}$ omega- 3 fatty acid from fish per $100 \mathrm{~g}$ or per serving (applies only to products packaged as single servings). If the product is processed in a way that can reduce the bioavailability of added fatty acids, this must be documented.

\section{Constipation - Dietary fibre}

Dietary fibre speeds the passage of food through the intestinal tract and a diet high in dietary fibre can thus lower the risk of constipation.

\section{Criteria}

A product making a claim regarding the connection between dietary fibre and constipation must meet keyhole symbol criteria where applicable (Appendix 5). In other cases, the criterion for "high fibre" must be met $(3.5 \mathrm{~g}$ dietary fibre per $1000 \mathrm{~kJ}$, see Appendix 5). Normal daily consumption of the product must provide at least $5 \mathrm{~g}$ of dietary fibre. $^{7}$

According to keyhole symbol criteria, the total sugar content (mono- and disaccharides) in breakfast cereals must not exceed 13\%. This corresponds to approx. $10 \%$ added sugar in cereals containing only cereal grains. According to the Code, the same criteria for added sugars must also be met for other dry products. For (soft) breads, the added sugar content must not exceed 7\%. For breakfast cereals, the fat content must not exceed $10 \%$.

\footnotetext{
${ }^{6}$ Recommendation according to NNR 2004: 1 energy $\%$ omega-3 fatty acids. At an energy consumption of $2000 \mathrm{kcal}$, this corresponds to $2.2 \mathrm{~g}$ of omega- 3 fatty acids per day. Similarly to the requirement for "high in" vitamins and minerals, a product making the nutrition claim of "high in omega-3 fatty acids" must have a total content of omega-3 fatty acids corresponding to at least $30 \%$ of this amount (i.e. $0.7 \mathrm{~g}$ ) per $100 \mathrm{~g}$ or serving. For the nutrition claim of "contains omega-3 fatty acids", the requirement is half this amount. For claims regarding a reduced risk of atherosclerosis, a product must be "high in" omega-3 fatty acids from fish.

${ }^{7} 5 \mathrm{~g}$ dietary fibre corresponds to $20 \%$ of the minimum recommended daily intake of dietary fibre $(25 \mathrm{~g})$.
} 
If more than $20 \%$ of the fibre content is made up of added fibre concentrates or isolates, documentation on the laxative effect of these fibres must be provided.

\section{Osteoporosis - Calcium andlor vitamin D}

Calcium and/or vitamin D are important dietary factors for building bones. A nutritional diet high in calcium and/ or vitamin $\mathrm{D}$ can therefore reduce the risk of osteoporosis.

\section{Criteria}

A product making a claim regarding the connection between calcium and osteoporosis must be "high in" calcium and/or vitamin D (i.e. 30\% RDI per $100 \mathrm{~g}$ or serving $^{8}$ ) (Table 3, Appendix 5). Where applicable, the criteria for use of the keyhole symbol must also be met (Appendix 5).

\section{Caries - Sugarlfermentable carbohydrates}

Frequent intake of products containing sugar and other easily fermented carbohydrates contributes to the development of caries. Products that do not contain sugar and other fermentable carbohydrates can therefore reduce the risk of caries.

\section{Criteria}

The connection between caries and fermentable carbohydrates is primarily applicable to beverages that are completely free of fermentable carbohydrates.

\section{Iron deficiency - Iron}

The intake of iron through diet is important, especially for people with high iron requirements. A nutritionally balanced diet high in iron can thereby reduce the risk for iron deficiency.

\section{Criteria}

Meat, fish, shellfish and poultry products contain haemiron with high bioavailability. These products are therefore considered suitable for claims regarding iron deficiency if the iron content corresponds to a "significant amount" (i.e. 15\% RDI per $100 \mathrm{~g}$ or serving, 9 Appendix 5, Table 3). Breads and bread mixes, coarsely ground flours, cereal flakes, breakfast cereals, fruit, vegetables and legumes making this claim must be "high in" iron (i.e. $30 \%$ RDI per $100 \mathrm{~g}_{\text {or serving }}^{8}$ ).

The iron content for all products must be based on the finished eating weight. For beans, this means it applies to

\footnotetext{
${ }^{8}$ Applies only to products packaged as single servings. Exceptions to this are milk and yoghurt, where claims may also be made on larger packages of the product providing that one normal serving contains at least $30 \%$ RDI.

${ }^{9}$ Applies only to products packaged as single servings.
}

cooked and not dry beans. For flour (and bread mixes), it means the breads baked with the flour and not the dry flour.

The criteria for using the keyhole symbol must be met where applicable, and the fat content must not exceed $10 \%$.

\section{Coronary heart disease - Wholegrain ${ }^{10}$}

Epidemiological studies have shown a connection between a high intake of wholegrain cereal products, healthy lifestyles and a lower incidence of (coronary) heart disease.

\section{Criteria}

A product making a claim regarding a connection between wholegrains and (coronary) heart disease must have a wholegrain content of at least $50 \%$ calculated on the product's dry weight. The criteria for use of the keyhole symbol must also be met where applicable (Appendix 5). This means a wholegrain content of $100 \%$ for flours, flakes and cereal grains, and two-thirds wholegrain for the flour base of breakfast cereals, a maximum total sugar content (total mono- and disaccharides) of $13 \%$ for breakfast cereals, gruel and porridge (not including baby foods) (corresponding to $10 \%$ added sugar for pure grain products), and a maximum of $10 \%$ fat in breads, crackers and rusks, and pasta products. According to the Code, also breakfast cereals should contain at most $10 \%$ fat. Products such as granola bars, etc., must meet the same criteria as breakfast cereals.

If a product uses a description such as "wholegrain bread" or similar, regulations regarding declaration of ingredients (SLVFS 1993:19) require statement of how much of the product is wholegrain. A product making a claim regarding the connection between (coronary) heart disease and wholegrain must also state the percentage based on dry weight. Declaration of a product's ingredients can be formulated as follows: "Water, wheat flour, wholegrain rye flour ( $\mathrm{X} \%$, equivalent to $\mathrm{Y} \%$ based on dry weight), sugar, salt."

It is desirable that expressions like "wholegrain bread", "wholegrain pasta", " wholegrain flakes", etc., be used only for products that meet the above criteria. For products that do not meet the above criteria the percentage of wholegrain may be stated in a less emphatic manner, e.g. in the list of ingredients, providing the wholegrain content constitutes at least $25 \%$ of the product's dry weight.

Wholegrain refers here to intact or ground whole seed kernels (i.e. cereal grains where all components contained in the grain seed, along with the seed shell, are included) of wheat, oats, barley and rye.

\footnotetext{
${ }^{10} \mathrm{New}$ connection introduced in this version of the Code.
} 
Table 2. Examples of appropriate wording for generic reduction of disease risk claims

I A nutritionally balanced diet with a well-adapted energy content is a key factor in maintaining one's weight. Product $X$ has a lower energy content than corresponding normal products.

$2^{\mathrm{a}} \quad$ (a) A nutritionally balanced diet with a low saturated fat content contributes to lower cholesterol levels in the blood and can thereby reduce the risk of cardiovascular disease/atherosclerosis. Product $Y$ has a low saturated fat content. (b) A nutritionally balanced diet high in soluble fibres from oats (beta-glucans) can contribute to lower cholesterol levels in the blood and thereby to a reduced risk of cardiovascular disease/atherosclerosis/hardening of the arteries. Product $Z$ is high in soluble oat fibres (beta-glucans).

$3^{\text {b }}$ A nutritionally balanced diet with a low sodium/salt content can contribute to lower blood pressure and thereby to a reduced risk of cardiovascular disease/ atherosclerosis. Product $\mathrm{XX}$ has a lower sodium/salt content than corresponding normal products.

4 A nutritionally balanced diet high in long omega-3 fatty acids from fish and fish products reduces the risk of cardiovascular disease/atherosclerosis. Product $Y Y$ is high in long omega-3 fatty acids.

5 A nutritionally balanced diet high in dietary fibre is important for maintaining bowel regularity and reduces the risk of constipation. Product ZZ is high in dietary fibre.

6 A nutritionally balanced diet high in (a) calcium, (b) vitamin D, (c) calcium and vitamin D reduces the risk of osteoporosis. Product XXX is high in (a) calcium, (b) vitamin D, (c) calcium and vitamin D.

7 Frequent consumption of products containing regular sugar (or other carbohydrates that are easily broken down by bacteria in the mouth) increases the risk for caries. Product YYY contains no sugar.

8 A nutritionally balanced diet high in iron reduces the risk for iron deficiency. Product ZZZ is high in iron.

$9^{c}$ A healthy lifestyle and well-balanced diet high in wholegrain products (a) reduces the risk of coronary heart disease, (b) reduces the risk of heart disease. Product $X X X X$ has a high wholegrain content (Y\% wholegrain).

${ }^{a}$ Claims regarding this connection can be worded to state $(I)$ the connection between hard fats or certain types of dietary fibre and reduction of the risk of cardiovascular disease/atherosclerosis, or (2) only the connection between hard fats or certain types of dietary fibre and blood cholesterol levels. When using the first alternative, the claim should clearly state that it is the risk factor "cholesterol level in the blood" that affects the risk of disease.

b A claim must be worded to clearly state that it is the risk factor "high blood pressure" that affects the risk of disease.

c A new claim introduced in this version of the Code. A claim must be formulated according to one of the alternatives given here.

\section{Fruit and/or vegetables}

Epidemiological studies suggest a connection between a high intake of fruit and vegetables and reduced incidence of cardiovascular disease and certain types of cancer. The picture is complicated, however, when it comes to cancer. A possible health claim regarding a reduced risk of disease is under discussion. Until further notice, producers and marketers are referred to the National Food Administration recommendation regarding the intake of $0.5 \mathrm{~kg}$ of fruit and vegetables ${ }^{11}$ daily, which can be used in the marketing and labelling of foods.

\section{Appendix 3. Product-specific physiological claims: evaluation of the scientific documentation}

For the documentation substantiating a product-specific physiological claim (PFP), the scientific quality must be documented by a statement from an independent panel of experts appointed by the SNF Research Committee. The task of the Research Committee is to ensure that review of the documentation's scientific quality and relevance in relation to the health benefits the marketing wishes to present is carried out when an application for evaluation is made and documentation provided. A panel of experts comprising at least three internationally well-reputed

\footnotetext{
$\overline{{ }^{11} \text { Does }}$ not include potatoes.
}

researchers in the field is appointed by the Research Committee. The panel's task is to issue a written statement regarding the scientific quality of the documentation in relation to the desired type of claim. The evaluation shall, however, not dictate the exact wording of a claim. This is the responsibility of the company, preferably after consultation, e.g. with SNF. The process for evaluation of scientific documentation by $\mathrm{SNF}^{12}$ is illustrated in Fig. 1 and is described in more detail below. For applications for PFP claims regarding a product's physiological effect on blood sugar level, a simplified procedure is used. For more information, please contact SNF (info@snf.ideon.se, tel +46 (0)46-286-2284).

\section{Review procedure}

The evaluation will be carried out as follows:

1) The scientific information on which a productspecific physiological claim for a food is based is evaluated on receipt of an application from the company intending to make such a claim in the marketing.

\footnotetext{
$\overline{{ }^{12} \text { The }}$ Assessment Board for Diet-health Information has a completely different task, namely to assess complaints and applications regarding marketing actions in relation to the selfregulating programme. For more information, see Appendix 6.
} 


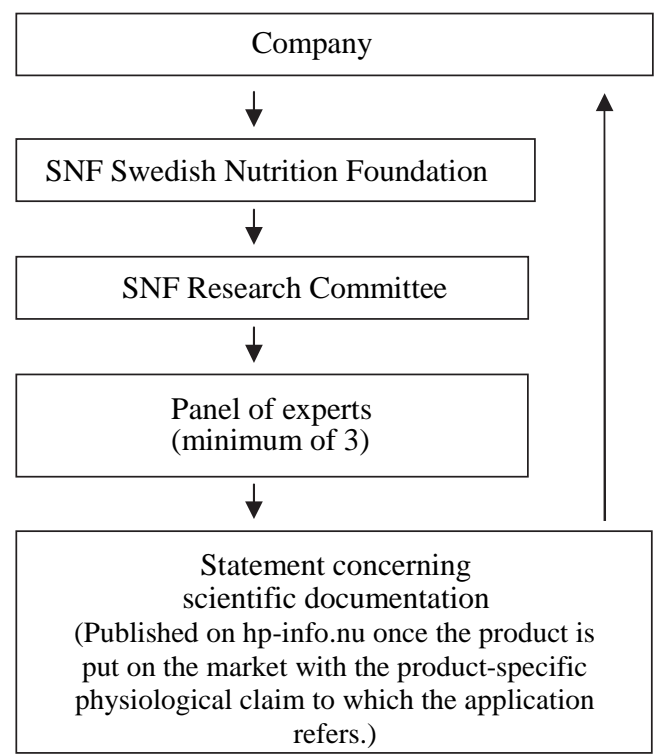

Fig. 1. General model for processing of applications for productspecific physiological claims.

2) SNF is responsible for initiating the evaluation process as soon as an application is received.

3) From a list of suitable experts, a panel of at least three experts will be appointed by the SNF Research Committee. The experts will be appointed within 4 working weeks and after having informed the Applicant in order to ascertain whether any expert may be challenged on grounds of partiality. One of the experts will be appointed as chairman. The Research Committee is responsible for ensuring that the composition of the expert panel is balanced and independent.

4) The evaluation will primarily include and be founded on human intervention studies on which the physiological effect to be claimed in the marketing is based. The number of studies necessary will be decided from case to case, depending on how wellestablished the physiological effect is considered to be. Background information such as animal studies may be used, when relevant, as supportive documentation and must be provided to the experts on request.

5) The evaluation will consider the scientific documentation in relation to the type of claim the Applicant wishes to make - not the exact wording or other formulation of the claim.

6) The evaluation shall be completed within 90 days of receiving the documentation. If additional time is needed, for example due to the scope of the documentation, an agreement will be reached from case to case. The expert panel must aim for a unanimous evaluation. If this is not possible, a majority decision is reached with right to express a dissenting opinion in writing.

7) The Applicant must be given an opportunity to comment on the evaluation before it is finalized.

8) If the Applicant does not accept the evaluation of the expert panel, and reports this to SNF within 2 weeks, a new expert panel must be appointed, after renewed consideration by the Research Committee, with the assignment of making a new evaluation. This shall be based on the report of the original panel together with comments and any additional documentation from the Applicant.

9) The assignment of the expert panel consists of judging whether the submitted documentation is qualitatively and quantitatively sufficient in relation to the health benefit the company intends to claim in the marketing. The responsibilities of SNF and its Research Committee shall be limited to coordination of the evaluation process and a decision as to whether to handle an application and appoint an expert panel. The Research Committee will also decide whether there are objective reasons to appoint a new expert panel, at the request of the Applicant Company, in accordance with point 8 .

10) The evaluation must be carried out confidentially. The evaluation report will become public if and when the product is put on the market with a product-specific physiological claim according to the assessed application.

11) SNF will decide a fee for the evaluation, which must be paid to SNF together with an administrative fee.

12) In labelling and marketing it is permitted to state that the product has undergone evaluation of the scientific documentation according to the Code. This must be stated in a standardized text: "Documentation supporting the health benefits of this product has been evaluated in accordance with the Food Sector's Code of Practice hp-info.nu". Neither SNF nor the experts' names may be mentioned in the marketing.

13) Appeals against the treatment of the application by the Research Committee, according to 9 above, are to be lodged with the Assessment Board for DietHealth Information (BKH).

14) The Research Committee can, if the scientific situation warrants, decide upon a renewed investigation. 
15) The evaluation will in addition follow applicable parts of Council of Europe's Policy Statements concerning Nutrition, Food Safety and Consumer Health: Guidelines Concerning Scientific Substantiation of Health-Related Claims for Functional Foods (can be downloaded in pdf format from www.snf.ideon.se).
Nils-Georg Asp

SNF Swedish Nutrition Foundation

Ideon Science Park

SE-223 70 Lund

Sweden

Tel: +46462862280

Fax: +46462862281

E-mail: asp@snf.ideon.se 